\title{
Study of Indoor PM2.5 and Volatile Organic Compounds Concentration in Selected Rural and Urban Areas of Zambia
}

\author{
David Mulenga*, Hebert Tato Nyirenda, Prispa Mwila, Chibangula M. Chileshe, Seter Siziya \\ Clinical Medical Sciences, Copperbelt University - Michael Chilufya Sata School of Medicine, Ndola, Zambia \\ *Corresponding author: davykdn@gmail.com
}

\begin{abstract}
Background: High levels of household air pollution (HAP) occur in houses of many developing countries due to combustion of biomass fuels (wood, charcoal, cow dung, crop residues) in the households in open fires or inefficient stoves. Particulate Matter (PM2.5) and Volatile Organic Compounds (VOCs) are among the significant pollutants that are generated and can adversely affect the health of the exposed. Therefore, we monitored PM2.5 and VOC in selected rural and urban areas of the Copperbelt province of Zambia in order to measure the magnitude and correlates of HAP concentration levels. Methods: Indoor PM2.5 particles $\leq 2.5 \mu \mathrm{g}$ in diameter (PM2.5) and VOCs were measured in 1,170 dwelling houses using Foobot (Model: FBT0002100 FCC ID: 2ADTK-FBT0002100, China). A standard questionnaire to capture the background and cooking characteristics such as kitchen type, fuel type and location of house in relation to ambient air pollution source was used. Data analysis using SPSS version 16 and EPIINFO were used at statistical significance level of 95\% confidence interval. Results: Biomass fuel use in our study area was the dominant source of household energy for cooking. Mean indoor PM2.5 varied greatly between households depending on fuel and kitchen type while the variations in VOC were not that much. Concentration levels for PM2.5 varied between $79 \mu \mathrm{g} / \mathrm{m}^{3}$ and $921 \mu \mathrm{g} / \mathrm{m}^{3}$, with an overall mean (SD) for daily average of $444.5 \mu \mathrm{g} / \mathrm{m}^{3}$ (170.2) while for VOC concentration levels ranged from $245 \mathrm{ppb}$ to $393 \mathrm{ppb}$ with an overall mean (SD) for daily average of $342 \mathrm{ppb}(25.3)$. The median (Q1, Q2) indoor PM2.5 during cooking time was $501(411,686) \mu \mathrm{g} / \mathrm{m}^{3}$ and daily average $393(303,578) \mu \mathrm{g} / \mathrm{m}^{3}$ while VOC daily average was $343(320,363) \mathrm{ppb}$ concentrations in the entire study population. Conclusion: Household air pollution mean concentrations in rural and urban settings of Ndola and Masaiti excessively exceed the WHO guidelines; hence continued efforts through research and advocacy are needed to mitigate the health damaging levels of household air pollution.
\end{abstract}

Keywords: household air pollution, particulate matter, volatile organic compounds, biomass

Cite This Article: David Mulenga, Hebert Tato Nyirenda, Prispa Mwila, Chibangula M. Chileshe, and Seter Siziya, "Study of Indoor PM2.5 and Volatile Organic Compounds Concentration in Selected Rural and Urban Areas of Zambia." Journal of Environment Pollution and Human Health, vol. 6, no. 2 (2018): 62-67. doi: 10.12691/jephh-6-2-3.

\section{Introduction}

Public Health recognizes household air pollution (HAP) as a vital determinant of health. Indoor air pollution (IAP) has been ranked fourth in terms of global burden when compared with 67 risk factors contributing to the Global Burden of Disease calculations. Household air pollution (HAP) is currently the leading environmental risk factor for global burden of disease [1]. Evidence exists of an association between exposure to elevated indoor air pollution levels and adverse health outcomes [2,3]. Exposure to indoor air pollution has been shown to have a substantial role in respiratory diseases, cardiovascular ill health, cataract and adverse pregnancy outcomes $[4,5,6,7]$.

Access to less polluting fuel is limited to majority of population in Sub-Saharan Africa (SSA) [8]. This is because; household air pollution (HAP) receives limited attention from policy makers and researchers. It is not considered as a problem since it is a traditional situation that has prevailed for centuries as such, linkage between cooking fuel pollution and health is by no means direct and simple to grasp. As a result, over 7 million people in SSA still depend on solid fuel for cooking [9], in Zambia more than three quarters of the population use solid fuels for cooking and heating their houses [wood (50.2\%) and charcoal (37.1\%)] and only $12.3 \%$ use electricity for this purpose [10] resulting in high indoor concentrations of HAP posing a high risk to the exposed.

This study therefore, aims at assessing household air pollution and its main predictors by measuring the mean indoor PM2.5 and VOC concentrations levels as indicators of HAP in the rural and urban settings of Zambia. PM2.5 are the smallest particles with a diameter of $\geq 2.5 \mu \mathrm{g}$ and they have the greatest health damaging potential. They are emitted from tobacco smoke, burning solid fuels and diesel engines [11]. VOCs are contained in woodsmoke 
and increased VOC has been shown to increase levels of oxidative stress [12]. Exposure to VOC among general population and pregnant women has been studied in the US, but little is known of VOC exposure among the general population in developing countries like Zambia [13].

Most studies involving association of indoor air pollution and health outcomes have been conducted in high-income countries and only little information is available in low-and middle -income countries despite the magnitude of the indoor air pollution problem in these populations. In sub-Saharan African countries like Zambia, use of solid fuels is very common because it is linked to poverty levels and statistics show that use of biomass as domestic energy in these populations ranges from $50 \%$ to as high as $95 \%$ in some rural communities [14]. This high proportion of biomass use in these countries has been implicated in respiratory diseases, cardiovascular ill health and pregnancy adverse outcomes in the countries where household monitoring of indoor pollutants has been conducted. It is for this reason that this study was conducted. The results of the study will help to improve the levels of information, and establish a baseline record of the evidence of the magnitude of MP2.5 and VOC in rural and urban households in Zambia. The knowledge that will be gained from this study will then provide empiric data that can be used to identify gaps and broaden the scope of research in this important subject.

\section{Materials and Methods}

\subsection{Study Area}

The study was conducted in Ndola and Masaiti in the Copperbelt province of Zambia. Ndola is predominantly an urban setting with a population of 551,910. The majority population of Ndola falls between low and middle social economic status, on the other hand the population of Masaiti (estimated population size 118,548) is predominantly rural (Zambia census projection report 2011 - 2035). The study households were divided into rural consisted of households in Masaiti district [ $n=481]$ and urban households in Ndola [n=689] (Table 1) according to the 2017 Ministry of Health Master Listing File of health facilities in Zambia.

Table 1. Showing total populations and specific residential areas selected for the study

\begin{tabular}{|c|c|c|c|}
\hline Study sites & $\begin{array}{c}2017 \text { total } \\
\text { populations }\end{array}$ & Selected area & Type of area \\
\hline $\begin{array}{l}\text { Masaiti } \\
\text { (Rural) }\end{array}$ & 118,548 & $\begin{array}{c}\text { Chikumbi } \\
\text { Kambowa } \\
\text { Mishikishi } \\
\text { Njelemani } \\
\text { Fiwale } \\
\end{array}$ & Rural \\
\hline $\begin{array}{l}\text { Ndola } \\
\text { (Urban) }\end{array}$ & 551,910 & $\begin{array}{c}\text { Kaniki } \\
\text { Lubuto } \\
\text { Mahatma Gandhi } \\
\text { Twapia }\end{array}$ & Urban \\
\hline
\end{tabular}

The Tropical Disease Research Centre Ethics Committee based in Ndola approved the study. After consenting by signing to allow the study team to conduct an assessment of the indoor air pollutant levels (PM2.5 and VOCs) in the individual's houses, a standard questionnaire was administered to the 1,170 consenting household members to establish the household features and cooking characteristics. The study was conducted between January and October, 2017. The target measurement duration was 24h and the measurement was apportioned before cooking, during cooking and after cooking.

\subsection{Measurement of Indoor MP2.5 and VOC Concentration Levels}

PM2.5 and VOC were measured using Foobot (Model: FBT0002100 FCC ID: 2ADTK-FBT0002100, China), a small portable indoor air quality (IAQ) monitoring device, with classy LED lights which allow real time air quality reading using 6 sensors for particulates (PM2.5), volatile organic compounds (VOCs), temperature, humidity, and carbon dioxide detection [15,16,17] was used in the measurement of indoor air pollution. The device is calibrated on the assembly line and also calibrates itself after 6 days to suit the environment. It has a mobile app for indoor air quality (IAQ) reports and charts to be sent to smartphones. In house the device was placed $125 \mathrm{~cm}$ above the floor (this height relates to the approximate edge of the active cooking area) and left to take readings for 24h apportioned as PM2.5 and VOC concentration levels the period before cooking, during cooking period and after cooking period. The daily average for PM2.5 and VOC were also calculated in $\mathrm{mg} / \mathrm{m} 3$ and $\mathrm{ppb}$ respectively.

\subsection{Data Management and Analysis}

To enter and clean data the Epi Info version 6.04 statistical package was used and a database was created at the start of the project for cross checking of IDs of participants and household numbers and for adding new households during the project. In addition, consistency and completeness of each questionnaire was checked. Data were analyzed using EPIINFO (version 6.04; Center for Diseases Control and Prevention, Atlanta, GA, USA and World Health Organization, Geneva, Switzerland), and SPSS (version 16; SPSS Inc., Chicago, IL, USA). Mean values at 95\% CI of PM2.5 and VOC concentrations were calculated to compare data. PM2.5 and VOC concentrations were transformed into $\log 10$ to meet the assumptions of normality to assess if mean PM2.5 and VOC concentrations differ by selected variables.

\section{Results}

A total of 1,210 households were listed for the study but only 1,170 households were finally included in the study for analysis. Forty households (3.3\%) were excluded from the analysis due to incompleteness of data and not having a member of the family with a consenting age present at home at the time of the visit by the study team.

\subsection{Household and Cooking Characteristics}

Biomass fuel was the main source of cooking fuel. More than half the population in the rural area (56.2\%) 
used charcoal. Wood was used by over one third (36.2\%) and only $2.5 \%$ used electricity in the rural. In the urban area slightly more than half $(50.9 \%)$ of the population used charcoal and only $12.4 \%$ used electricity. The types of kitchens observed in the overall population included enclosed kitchen (40.1\%), semi-enclosed (16.9\%), open space (20.3\%) and other unspecified kitchens (22.7\%). Table 2 and Table 3 show the type of kitchen and cooking fuel observed in the rural and urban population of the study.

Table 2. Showing fuel types used in rural, urban and overall study population

\begin{tabular}{|c|c|c|c|c|c|c|}
\hline \multirow{2}{*}{ Fuel type } & \multicolumn{2}{|c|}{ Rural } & \multicolumn{2}{|c|}{ Urban } & \multicolumn{2}{|c|}{ Overall } \\
\hline & $\%$ & $95 \%$ CI & $\%$ & $95 \% \mathrm{CI}$ & $\%$ & $95 \%$ CI \\
\hline Wood & 36.2 & [32.2-40.4] & 8 & {$[6.2-10.2]$} & 14.8 & [13.1-16.7] \\
\hline Crop residue & 3.7 & {$[2.4-5.8]$} & 1.6 & {$[0.9-2.8]$} & 2.1 & {$[1.4-3.1]$} \\
\hline Charcoal & 56.3 & [52.1-60.5] & 50.9 & [47.3-54.6] & 52.3 & [49.3-55.2] \\
\hline Electricity & 2.5 & {$[1.5-4.2]$} & 15.5 & [13.1-18.4] & 12.4 & {$[10.5-14.6]$} \\
\hline Combination of fuels & 1.2 & {$[0.6-2.7]$} & 23.9 & {$[21.0-27.2]$} & 18.4 & [16.2-20.9] \\
\hline Total & 100 & & 100 & & 100 & \\
\hline
\end{tabular}

Table 3. Showing types of kitchens observed in the rural and urban population of the study

\begin{tabular}{|c|c|c|c|c|c|c|}
\hline \multirow{2}{*}{ Kitchen type } & \multicolumn{2}{|c|}{ Rural } & \multicolumn{2}{|c|}{ Urban } & \multicolumn{2}{|c|}{ Overall } \\
\hline & $\%$ & $95 \%$ CI & $\%$ & $95 \%$ CI & $\%$ & $95 \%$ CI \\
\hline Under a shed & 7.7 & [5.7-10.3] & 7.4 & {$[5.7-9.6]$} & 7.5 & [6.1-9.2] \\
\hline Semi-enclosed shelter & 16.6 & [13.7-20.1] & 17 & [14.4-19.9] & 16.9 & [14.8-19.2] \\
\hline Enclosed kitchen & 47.6 & [43.4-51.9] & 37.7 & [34.3-41.4] & 40.1 & [37.3-43.1] \\
\hline Open space & 14.3 & [11.6-17.6] & 22.2 & [19.3-25.4] & 20.3 & {$[18.0-22.8]$} \\
\hline Living room & 1.2 & [0.6-2.7] & 1.5 & {$[0.8-2.6]$} & 1.4 & [0.8-2.3] \\
\hline Others (specify) & 0.4 & {$[0.1-1.6]$} & 0.9 & [0.4-1.9] & 0.8 & {$[0.4-1.5]$} \\
\hline Total & 100 & & 100 & & 100 & \\
\hline
\end{tabular}

\subsection{Indoor PM2.5 and VOC Measurements}

The overall population median $(\mathrm{Q} 1, \mathrm{Q} 2)$ respectively observed for PM2.5 during cooking and daily average were $501 \mu \mathrm{g} / \mathrm{m}^{3}(411,686)$ and $393 \mu \mathrm{g} / \mathrm{m}^{3}(303,578)$ and for VOC the overall median for the daily average was 343 ppb (320, 363). Table 4 summarizes the population median (Q1, Q2) observed in the entire study population.

\subsection{Indoor PM2.5 and VOC Concentration Index}

The indoor PM2.5 and VOC concentration index for the entire study population with measurements apportioned before cooking, during cooking and after cooking is shown in Table 5.
The concentration levels for PM2.5 varied between 79 $\mu \mathrm{g} / \mathrm{m}^{3}$ and $921 \mu \mathrm{g} / \mathrm{m}^{3}$, with an overall mean (SD) for daily average of $444.5 \mu \mathrm{g} / \mathrm{m}^{3}$ (170.2) while for VOC concentration levels ranged from $245 \mathrm{ppb}$ to $393 \mathrm{ppb}$ with an overall mean (SD) for daily average of $342 \mathrm{ppb}$ (25.3).

Table 4. Showing the median (Q1, Q2) indoor PM2.5 (during cooking and daily average) and VOC (daily average) concentrations and in the entire study population

\begin{tabular}{l|c|cc}
\hline HAP & \multicolumn{3}{|c}{ Overall } \\
\hline & Median & Q1 & Q2 \\
\hline PM2.5 $\left(\mu \mathrm{g} / \mathrm{m}^{3}\right)$ & & & 686 \\
During cooking & 501 & 411 & 578 \\
Daily average & 393 & 303 & \\
VOC (ppb) & & & 363 \\
Daily average & 343 & 320 & \\
\hline
\end{tabular}

Table 5. Showing indoor PM2.5 and VOC concentration index for the entire study population apportioned before cooking, during cooking and after cooking periods

\begin{tabular}{|c|c|c|c|c|c|c|}
\hline Sampling duration & PM2.5 $\left(\mu \mathrm{g} / \mathrm{m}^{3}\right)$ & From & To & VOC (ppb) & From & To \\
\hline \multirow{3}{*}{$\begin{array}{l}\text { Before cooking } \\
8-10 \mathrm{~h}\end{array}$} & Low & 79 & 179 & Low & 245 & 320 \\
\hline & Moderate & 180 & 344 & Moderate & 321 & 350 \\
\hline & High & 345 & 664 & High & 351 & 383 \\
\hline \multirow{3}{*}{$\begin{array}{l}\text { During cooking } \\
2-4 \mathrm{~h}\end{array}$} & Low & 335 & 432 & Low & 297 & 322 \\
\hline & Moderate & 433 & 601 & Moderate & 323 & 353 \\
\hline & High & 602 & 921 & High & 354 & 393 \\
\hline \multirow{3}{*}{$\begin{array}{l}\text { After cooking } \\
4-6 \mathrm{~h}\end{array}$} & Low & 262 & 369 & Low & 272 & 333 \\
\hline & Moderate & 370 & 535 & Moderate & 334 & 363 \\
\hline & High & 536 & 855 & High & 364 & 393 \\
\hline \multirow{3}{*}{$\begin{array}{l}\text { Daily average } \\
24 \mathrm{~h}\end{array}$} & Low & 226 & 328 & Low & 300 & 325 \\
\hline & Moderate & 329 & 493 & Moderate & 326 & 355 \\
\hline & High & 494 & 813 & High & 356 & 385 \\
\hline
\end{tabular}


Table 6. Showing Mean differences of VOC and PM2.5 concentration levels between rural and urban households

\begin{tabular}{|c|c|c|c|c|c|c|c|c|}
\hline Factor & Group & Obs & Mean & Std. Err. & Std. Dev. & [95\% Conf. & Interval] & P-value \\
\hline \multicolumn{9}{|l|}{ VOC } \\
\hline & Rural & 481 & 136.2204 & 0.460482 & 10.09916 & 135.3156 & 137.1252 & \\
\hline & Urban & 689 & 137.0711 & 0.3845288 & 10.09342 & 136.3161 & 137.8261 & \\
\hline & combined & 1170 & 136.7214 & 0.2952805 & 10.10015 & 136.142 & 137.3007 & 0.0782 \\
\hline & diff & & -0.850743 & 0.5998611 & & -2.027669 & 0.3261824 & \\
\hline \multirow[t]{4}{*}{ PM2.5 } & Rural & 481 & 83.12682 & 1.606137 & 35.22532 & 79.97089 & 86.28275 & \\
\hline & Urban & 689 & 78.38171 & 1.259896 & 33.07076 & 75.90801 & 80.85541 & \\
\hline & combined & 1170 & 80.33248 & 0.995123 & 34.03844 & 78.38005 & 82.28491 & 0.0095 \\
\hline & diff & & 4.745106 & 2.018559 & & 0.7847003 & 8.705513 & \\
\hline
\end{tabular}

\subsection{Mean Difference}

There was a significant difference in the mean indoor PM2.5 concentration levels between rural and urban areas. However, no difference observed for the mean indoor VOCs concentration levels.

Table 7. Showing variations in the mean indoor PM2.5 and VOC before cooking, during cooking and after cooking between rural and urban area

\begin{tabular}{|c|c|c|c|c|c|c|}
\hline \multirow[b]{2}{*}{ PM2.5 } & \multicolumn{2}{|c|}{ Rural } & \multicolumn{2}{|c|}{ Urban } & \multicolumn{2}{|c|}{ Total } \\
\hline & Mean $\left(\mu \mathrm{g} / \mathrm{m}^{3}\right)$ & Std. Dev. & Mean $\left(\mu \mathrm{g} / \mathrm{m}^{3}\right)$ & Std. Dev. & Mean $(\mu \mathrm{g} / \mathrm{m} 3)$ & Std. Dev. \\
\hline Before cooking & 309.7 & 176.1 & 286.2 & 165.3 & 295.8 & 170.1 \\
\hline During cooking & 566.1 & 176.1 & 542.4 & 165.3 & 552.2 & 170.2 \\
\hline After cooking & 500.1 & 176.2 & 475.4 & 165.5 & 485.5 & 170.4 \\
\hline Daily average & 458.6 & 176.1 & 434.7 & 165.4 & 444.5 & 170.2 \\
\hline VOC & Mean (ppb) & & Mean (ppb) & & Mean (ppb) & \\
\hline Before cooking & 335.6 & 25.2 & 337.8 & 25.4 & 336.9 & 25.3 \\
\hline During cooking & 338.1 & 25.2 & 340.3 & 25.2 & 339.4 & 25.2 \\
\hline After cooking & 348.1 & 25.2 & 350 & 25.5 & 349.2 & 25.4 \\
\hline Daily average & 340.6 & 25.2 & 342.7 & 25.4 & 342 & 25.3 \\
\hline
\end{tabular}

Table 8. Showing mean (SD) indoor PM2.5 and VOC variations by fuel types and kitchen types, Ndola and Masaiti, Zambia (n = 1170)

\begin{tabular}{|c|c|c|c|c|c|c|c|c|c|c|c|c|c|c|c|}
\hline \multicolumn{16}{|c|}{ PM2.5 $\mu \mathrm{g} / \mathrm{m}^{3}$} \\
\hline \multirow[b]{2}{*}{ Variable } & \multicolumn{5}{|c|}{ Rural } & \multicolumn{5}{|c|}{ Urban } & \multicolumn{5}{|c|}{ Total } \\
\hline & Obs & Mean & Std. Dev. & Min & Max & Obs & Mean & Std. Dev. & Min & Max & Obs & Mean & Std. Dev. & Min & Max \\
\hline \multicolumn{16}{|l|}{ Fuel type } \\
\hline Charcoal & 271 & 319.89 & 170.4 & 79 & 664 & 351 & 299.41 & 166.4 & 79 & 664 & 622 & 308.3 & 168.29 & 79 & 664 \\
\hline Wood & 174 & 314 & 182.5 & 79 & 659 & 55 & 249.82 & 170.5 & 79 & 629 & 229 & 298.6 & 181.43 & 79 & 659 \\
\hline Crop Res. & 18 & 227.89 & 167.1 & 84 & 619 & 11 & 316.73 & 187.7 & 84 & 634 & 29 & 261.6 & 177.38 & 84 & 634 \\
\hline Electricity & 12 & 182.58 & 150 & 79 & 584 & 107 & 266.33 & 149.3 & 84 & 654 & 119 & 257.9 & 150.86 & 79 & 654 \\
\hline Combinations & 6 & 220.67 & 184.7 & 99 & 584 & 165 & 281.21 & 168.2 & 79 & 655 & 171 & 279.1 & 168.54 & 79 & 655 \\
\hline \multicolumn{16}{|l|}{ Kitchen type } \\
\hline Enclosed & 235 & 304.75 & 167.6 & 79 & 664 & 270 & 295.77 & 166.3 & 79 & 664 & 505 & 300 & 166.82 & 79 & 664 \\
\hline Separate room & 186 & 321.97 & 190.8 & 79 & 664 & 321 & 287 & 166.1 & 79 & 655 & 507 & 299.8 & 176.17 & 79 & 664 \\
\hline Open space & 60 & 290.67 & 160.7 & 79 & 614 & 98 & 257.56 & 158.2 & 79 & 654 & 158 & 270.1 & 159.44 & 79 & 654 \\
\hline \multicolumn{16}{|l|}{ VOC (ppb) } \\
\hline & \multicolumn{5}{|c|}{ Rural } & \multicolumn{5}{|c|}{ Urban } & \multicolumn{5}{|c|}{ Total } \\
\hline Variable & Obs & Mean & SD. & Min & Max & Obs & Mean & SD & Min & Max & Obs & Mean & SD & Min & Max \\
\hline \multicolumn{16}{|l|}{ Fuel type } \\
\hline Charcoal & 622 & 336.77 & 25.07 & 295 & 380 & 271 & 335.16 & 24.06 & 295 & 380 & 351 & 338 & 25.79 & 295 & 380 \\
\hline Wood & 229 & 338.73 & 26.38 & 295 & 380 & 174 & 336.92 & 26.94 & 295 & 380 & 55 & 344.5 & 23.87 & 298 & 380 \\
\hline Crop Res. & 29 & 336 & 28.45 & 295 & 380 & 18 & 329.94 & 27.52 & 295 & 380 & 11 & 345.9 & 28.36 & 300 & 380 \\
\hline Electricity & 119 & 338.24 & 22.99 & 295 & 380 & 12 & 339 & 27.17 & 295 & 375 & 107 & 338.1 & 22.61 & 295 & 380 \\
\hline Combinations & 171 & 335.63 & 26.1 & 245 & 383 & 6 & 344.83 & 19.43 & 328 & 375 & 165 & 335.3 & 26.3 & 245 & 383 \\
\hline \multicolumn{16}{|l|}{ Kitchen type } \\
\hline Enclosed & 270 & 337 & 25.86 & 245 & 380 & 235 & 334.36 & 25.82 & 295 & 380 & 505 & 335.8 & 25.847 & 245 & 380 \\
\hline Separate room & 321 & 338.58 & 25.15 & 295 & 383 & 186 & 337.9 & 24.64 & 295 & 380 & 507 & 338.3 & 24.941 & 295 & 383 \\
\hline Open space & 98 & 339.01 & 25.04 & 295 & 380 & 60 & 335.08 & 24.87 & 295 & 380 & 158 & 337.5 & 24.97 & 295 & 380 \\
\hline
\end{tabular}

Variations in HAP (PM2.5 and VOC) concentration levels.

Variations by time of the day (before cooking, during cooking and after cooking).

Variations by fuel and kitchen types. 
In the rural area charcoal recorded the highest mean PM2.5 concentrations of $319.89(\mathrm{SD} \pm 170.4) \mu \mathrm{g} / \mathrm{m}^{3}$ followed by wood which had $314(\mathrm{SD} \pm 182.5) \mu \mathrm{g} / \mathrm{m}^{3}$ while electricity only recorded $182.5(\mathrm{SD} \pm 150) \mu \mathrm{g} / \mathrm{m}^{3}$. In the urban area households using charcoal had 299.1 (SD \pm 166.4$) \mu \mathrm{g} / \mathrm{m}^{3}$, wood $249.82(\mathrm{SD} \pm 170.5) \mu \mathrm{g} / \mathrm{m}^{3}$ while electricity had $266.33(\mathrm{SD} \pm 149.3) \mu \mathrm{g} / \mathrm{m}^{3}$. The highest VOCs concentrations level was $380 \mathrm{ppb}$ and measured in households using biomass fuels for cooking. Kitchen type did not show any changes in the maximum concentration levels.

\section{Discussion}

The main variable in this research was the magnitude of particulate matter and volatile organic compounds in rural and urban selected areas of the Copperbelt province in Zambia. To the best of our knowledge this is the first study of this nature to be carried out in Zambia. The study found that almost all the study households used biomass fuels, mainly charcoal and firewood, but also crop residues and animal dung especially in the rural areas. The reported use of biomass fuel in the current study is consistent with the findings in many other studies conducted in developing countries $[18,19]$ where similar research work has been conducted. This is further supported by the work done by Dasappa indicating that access to electricity in sub-Saharan Africa (SSA) is only about $26 \%$ and falls to less than $1 \%$ in the rural areas [20]. This is a big challenge for poor populations where biomass is the main source of cooking energy because biomass fuels emit considerably more pollutants compared to fossil fuels. The size of the health risks associated with burning solid fuels in open fires and poor stoves may be as much as two- to three times greater compared to the risk associated with emissions from clean fuels [21].

The indoor measurements of household air pollution in the selected rural and urban settings of the Copperbelt province of Zambia have shown clearly that PM2.5 concentrations are well above WHO guidelines of $25 \mu \mathrm{g} / \mathrm{m}^{3}$ of 24h indoor monitoring [22] and confirm previous findings [23] in Zambia. Many studies by World Health Organization reporting on particulate matter and other gaseous pollutants for developing countries indicate pollutant concentrations exceeding the WHO guidelines by several orders of magnitude. This is because solid fuel is the dominant source of household cooking and heating energy in most households and Zambia is not an exception [10]. The high indoor PM2.5 concentration levels observed in Ndola and Masaiti households are an indication of high levels of biomass use in these populations. These findings are in accord with previous results in low income areas in other parts of the world $[24,25]$. Similarly, the indoor volatile organic compounds concentration levels observed in the current study are equally higher than the concentrations of VOCs seen in high income countries around the world [26].

Our current study observed that HAP varied according to the region, for instance there was a significant difference in the mean indoor PM2.5 concentration levels between rural and urban areas with the rural areas recording higher
PM2.5 indoor concentration levels compared to the urban areas. Similar observations elsewhere indicate that rural areas show a high concentration level of PM2.5 compared to the urban area [27]. This might be explained by a high use of biomass fuel for cooking in the rural compared to the urban areas. On the contrary, for the mean indoor VOCs, the urban area recorded a higher mean indoor concentration level compared to the rural area and this might be attributed to the explanation that complex mixtures of volatile and semi-volatile organic compounds are a preserve of modern buildings [28]. However, it is also important to note that the difference was not statistically significant.

For both PM2.5 and VOCs, high concentration levels were observed in households using biomass as cooking fuel and in households with an enclosed type of a kitchen inside the dwelling house. The higher measurements for both PM2.5 and VOCs were observed during cooking period, similar to the study by Zhao in which peak PM2.5 concentrations were observed during enhanced anthropogenic activities such as cooking. This finding is also in accord with the observation by Klepeis and colleagues [16] when using a Foobot in air quality measurements and further supported by the work by Zhang and colleagues [27] in which he explored the modelling of biomass burning emissions in relation to PM2.5 and Liu and colleagues [29] demonstrated that one of the major sources of VOCs in China is biomass burning.

The public health implication of our findings is that cheaper fuel options in any context are generally less efficient fuels; they produce more smoke, and tend to be used mainly by poor people who in most cases would be living in poorly designed houses. Cleaner fuel options like electricity are obviously the least polluting form of domestic energy (if households are geographically separated from power stations), but are too expensive for most people [30] who are the majority in developing countries and who end up exposed to the highly toxic emissions causing adverse health outcomes ranging from respiratory illness, cardiovascular ill health, low birth weight and other adverse birth outcomes.

\section{Conclusions}

Household air pollution concentration levels found in our current study are consistent with previous studies conducted in other low income countries around the world. The pollutant levels obtained indoors excessively exceed the recommended WHO standards. Therefore, interventions should target the determinants of household air pollution such as house construction, fuel type and location of house in relation to air pollution sources.

\section{Acknowledgements}

We would like to thank the residents of Masaiti and Ndola for allowing us to measure the levels of PM2.5 and VOCs in their houses and participating fully in the study. We are deeply grateful to the project research team. 


\section{References}

[1] Lim SS, Vos T, Flaxman AD, Danaei G, Shibuya K, Adair-Rohani $\mathrm{H}$, et al. A comparative risk assessment of burden of disease and injury attributable to 67 risk factors and risk factor clusters in 21 regions, 1990-2010: a systematic analysis for the Global Burden of Disease Study 2010. Lancet 2012; 380:2224-60.

[2] Pope DP, Mishra V, Thompson L, Siddiqui AR, Rehfuess EA, Weber M, and Bruce NG. Risk of Low Birth Weight and Stillbirth Associated with Indoor Air Pollution from Solid Fuel Use in Developing Countries. Epidemiol. Reviews Vol. 32, 2010.

[3] Wylie BJ, Kishashu Y, Matechi E, Zhou Z, Coull B, Abioye AI, et al. Maternal exposure to carbon monoxide and fine particulate matter during pregnancy in an urban Tanzanian cohort. Indoor Air. 2016; 27:136-146.

[4] Malley CS, Kuylenstierna JC, Vallack HW, Henze DK, Blencowe $\mathrm{H}$, Ashmore MR. Preterm birth associated with maternal fine particulate matter exposure: A global, regional and national assessment. Environment International. 2017; 101:173-182.

[5] Korten I, Ramsey K, Latzin P. Air pollution during pregnancy and lung development in the child. Paediatric Respiratory Reviews. 2017; 21:38-46.

[6] Langbein J. Firewood, smoke and respiratory diseases in developing countries-The neglected role of outdoor cooking. PLoS One. 2017;12: e0178631).

[7] Rao, N., Pachauri, S.,2017. Energy access and living standards: some observations on recent trends. Environ. Res. Lett. 12, e025011.

[8] Tumwesige V, Okello G, Semple impact of partial fuel switch on household air pollutants in Sub-Saharan Africa. Environmental pollution 231 (2017) 1021-1029.

[9] Zambia Demographic Health Survey, 2013-14.

[10] WHO, 2017 HAP. http//www.who.int/indoorair accessed on 15.10. 2017.

[11] Weinstein JR, Asteria-Penaloza R, Diaz-Artiga A, Davila G, Hammond KS, Ryde IT, Meyer JN, Benowitz N, Thompson LM. 2017. Exposure to polycyclic aromatic hydrocarbons and volatile organic compounds among recently pregnant rural Guatemalan women cooking and heating with solid fuels. International Journal of Hygiene and Environmental Health 220 (2017) 726-735.

[12] St. Helen G., Aguilar-Villalobos M, Cassidy B. E., Blount B. C., Bayer C., Hall D. B., Needham L. L., Hendry R. J., Naeher L. P. 2011. Characterization of Volatile Organic Compounds (vocs) Exposure from Cooking Fuels Among a Cohort of Pregnant Women in Trujillo, Peru. Am J Respir Crit Care Med 183; 2011 : A3894.

[13] Reddy A, Williams R, Johansson T. United nations development program. New York: 1997. Energy after rio: Prospects and challenges; p. 176.

[14] Sousan S, Koehler K, Hallett L, Peters TM, Aerosol Science and Technology: The Journal of the American Association for Aerosol Research 2017, 107: 123-133.
[15] Klepeis NE. et al., "The national human activity pattern survey (NHAPS): A resource for assessing exposure to environmental pollutants,” J. Exposure Sci. Environ. Epidemiol., vol. 11, no. 3, pp. 231-252, 2001.

[16] Utkarshani J, Tanvi B, William R, Krishnaprasad T, Amit S, and Maninder K. Investigation of an Indoor Air Quality Sensor for Asthma Management in Children. Vol. 1, no. 2, 2017

[17] Dasgupta, S., Huq, M., Khaliquzzaman, M., Pandey, K. and Wheeler, D. (2006) Indoor air quality for poor families: new evidence from Bangladesh, Indoor air, 16, 426-444.

[18] Rehfuess, E., Mehta, S. and Pru“ ss-Ustun, A. (2006) Assessing household solid fuel use: multiple implications for the millennium development goals, Environ. Health Perspect., 114, 373-378.

[19] Dasappa s Potential of biomass energy for electricity generation in sub-Saharan Africa (2011). Energy for Sustainable Development, Vol. 15 (3), 203-213.

[20] Chretien, J., Holland, W., Macklem, P., Murray, J. and Woolcock, A. (1984) Acute respiratory infections in children. A global public-health problem, N. Engl. J. Med., 310, 982-984.

[21] WHO, 2014. Global database of Household Air Pollution Measurements. Available: http://www.who.int/indoorair/health_impacts/databases_iap/en

[22] Brauer, M. et al. 2016. “Ambient Air Pollution Exposure Estimation for the Global Burden of Disease 2013.” Environmental Science \& Technology 50, no. 1: 79-88

[23] Edwards RD, Liu Y, He G, Yin Z Sinton J, Peabody J, et al., Household CO and PM measured as part of a review of China's National Improved Stoved Program, Indoor Air 2007;17:189-203.

[24] Balakrishnan K, Sambandam S, Ramaswamy P, Mehta KR. Exposure assessment for respirable particulates associated with household fuel use in rural districts of Andhra Pradesh, India. J Expo Anal Environ Epidemiol 2004; 14: S14-25.

[25] Alshaarawy O, Elbaz HA, Andrew ME (2016), Environment International Vols. 89-90;174-178.

[26] Zhao X, Zhang X, Xu X, Xu J, Meng W, Pu W (2009) Seasonal and diurnal variations of ambient PM2.5 concentrations in urban and rural environments in Beijing. Atmospheric Environment Vol. 43(18) 2893-2900.

[27] Smith KR, Bruce N, Balakrishnan K, Adair-Rohani H, Balmes J, Chafe Z, et al. 2014. Millions dead: how do we know and what does it mean? Methods used in the comparative risk assessment of household air pollution. Annu Rev Public Health 35:185-206.

[28] Zhang, J. and Smith, K.R. (2003) Indoor air pollution: a global concern, Br. Med. Bull., 68, 209-225.

[29] Liu Y, Shao, Fu Sihua, Zeng L, Tang D (2008), Source profiles of volatile organic compounds (VOCs) measured in China: Part I. Atmospheric Environment Vol. 42(25) 6247-6260.

[30] Rehfuess E, Fuel for Life: Household Energy and Health, World Health Organization, Geneva (2006). 